Article

\title{
Evaluation of Ion Exchange and Sorbing Materials for Their Adsorption/Desorption Performane towards Anthocyanins, Total Phenolics, and Sugars from a Grape Pomace Extract
}

\author{
Evangelos D. Trikas ${ }^{1,2}$, Rigini M. Papi ${ }^{2}$, Dimitrios A. Kyriakidis ${ }^{2}$ and George A. Zachariadis ${ }^{1, *}$ \\ 1 Laboratory of Analytical Chemistry, Department of Chemistry, Aristotle University, 54124 Thessaloniki, \\ Greece; trikas.vag@hotmail.com \\ 2 Laboratory of Biochemistry, Department of Chemistry, Aristotle University, 54124 Thessaloniki, Greece; \\ rigini@chem.auth.gr (R.M.P.); kyr@chem.auth.gr (D.A.K.) \\ * Correspondence: zacharia@chem.auth.gr; Tel.: +30-2310997707
}

Academic Editor: Juan F. García-Reyes

Received: 27 December 2016; Accepted: 15 March 2017; Published: 18 March 2017

\begin{abstract}
Byproducts of winery industries are treated, in many cases, as useless wastes constituting not only a major disposal problem but also not providing any additional profit to the industries. However, these byproducts could be utilized as a source of various phenolic compounds, such as anthocyanins, that could be used as nutraceuticals or natural colorants. Nine materials were tested and evaluated for their ability to retain and elute anthocyanins, total phenolics, and sugars from a grape pomace extract. The materials tested were the ion exchange Amberlite IRA $400 \mathrm{Cl}^{-}$, Lewatit TP 208 and Lewatit TP 260, and the sorbing Chromosorb G-HP, Amberite XAD 2, Zeocros CA 150, Chemviron Carbon, Oasis HLB (hydrophilic-lipophilic balance) and Isolute C8 end-capped (EC). The two materials with the higher anthocyanins recovery rate, Oasis HLB and Isolute C8 (EC), were further examined for their anthocyanin capacities which were calculated as $5.76 \mathrm{mg} \cdot \mathrm{cm}^{-3}$ and $3.06 \mathrm{mg} \cdot \mathrm{cm}^{-3}$ respectively. Furthermore, their behavior pattern towards anthocyanins of various molecular weights was investigated using a liquid chromatography coupled with mass spectrometry (LC-PDA-MS) system.
\end{abstract}

Keywords: grape pomace; anthocyanins; total phenolics; sugars; solid-phase extraction; mass spectrometry

\section{Introduction}

The wine making industry is a huge field with yearly worldwide growth. Grapes used for wine production contain a wide variety of valuable compounds, such as anthocyanins and other phenolic compounds. The majority of these compounds lie at the skin of the fruit. As a result, the byproducts remaining after the vinification procedure (grape pomace) contain a significant percentage of the total phenolic content of grapes. These phenolic compounds, present in wine byproducts, have been proved to be biologically active, possessing not only antioxidant properties [1-3], but a correlation between total phenolic content and antibacterial activity has also been demonstrated $[4,5]$.

Another important property of these compounds is that they are responsible for the colors of various fruits and nuts. Anthocyanins are not only responsible for the red color of grapes, but can also display other colorations like blue, purple, and orange. Now that the safety of many artificial pigments is questionable [6], the industry's demand for attractive and edible natural colorants has increased significantly $[7,8]$. The above characteristics, both biological properties and the ability to alter or enhance a product's color, make these compounds very valuable to the food industry. These could 
be used widely as food additives such as nutraceuticals, conservatives, or colorants. This indicates that a possible utilization of these byproducts could be of great commercial interest.

The extraction of these compounds from grape pomace is often performed with the use of acidified aqueous alcoholic solutions, mainly methanol or ethanol [9-13]. In order to obtain more phenolics-rich or purified extracts, the extraction procedure could be followed by other techniques, such as liquid-liquid extraction, filtration with special membranes, or the absorbance of these compounds on various materials (resins and ion exchange materials) using solid phase extraction [14-16].

Diaz-Reinoso et al. [17], used ultrafiltration and nanofiltration membranes in order to retain catechin, epicathehin, quercetin, gallic acid, and other compounds that were contained in their sample, distilled grape pomace pressing liquors (DGPPL). The recovery and concentration of antioxidants from winery wastes with the use of polymeric resins was also the objective of another study [18], while ion exchange and adsorbent resins were also used from Kammerer et al. [19], for the bounding of polyphenols from apple and grape crude plant extracts. The retrieval of trans-resveratrol from grape pomace with the use of macroporous resin was the subject of a research made by Wang [20], while Soto et al. [21], tried to adsorb polyphenols in activated charcoal.

Similar studies have also been made specifically in the field of anthocyanins. Extensive work has been conducted by Kraemer-Schafhalter et al. [22] that examines 16 different materials for their ability to adsorb and desorb anthocyanins. Since the anthocyanins exist in a variety of fruits and plants, it is expected that the research will be extended to a pleiad of matrices. So, apart from grape pomace $[23,24]$, the use of absorbent materials for the recovery of anthocyanins has been investigated also in blueberries [25,26], raspberries [27], black beans [28,29], orange pulp wash [30], and even calyces of Hibiscus sabdariffa flower [31].

The present study consisted of two parts. The objective of the first part was to evaluate nine different solid phase materials for their ability and easiness to retain and desorb anthocyanins, total phenolics, and sugars from an aqueous grape pomace extract, with a particular interest in their performance towards anthocyanins. A wide spectrum of materials, with different chemical and physical properties, were investigated including zeolite, anion and cation exchange resins, activated carbon, and polystyrene resins. In the second part of the study, the materials exhibiting best performance during anthocyanins tests were further investigated regarding their total capacity and their anthocyanins adsorption/desorption patterns using an LC-PDA-MS system.

\section{Materials and Methods}

\subsection{Reagents and Solutions}

All reagents were of analytical grade, and deionized water was used for extraction procedure and preparation of all aqueous solutions. The reagents used incuded methanol $(\mathrm{MeOH}, \mathrm{Chem}-\mathrm{Lab}$, Zedelgem, Belgium), ethanol (EtOH, Chem-Lab), ortho-phosphoric acid $\left(\mathrm{H}_{3} \mathrm{PO}_{4} 85 \%\right.$, Panreac, Barcelona, Spain), formic acid ( $\mathrm{HCOOH}$, Panreac), sodium hydroxide $(\mathrm{NaOH}$, Sigma-Aldrich, St. Louis, MO, USA), potassium chloride (KCl, J.T. Baker, Deventer, The Netherlands), hydrochloric acid $\left(\mathrm{HCl} 37 \%\right.$, Carlo Erba Reagents, Italy), acetic acid $\left(\mathrm{CH}_{3} \mathrm{COOH}\right.$, Panreac), sodium acetate $\left(\mathrm{CH}_{3} \mathrm{COONa}\right.$, J.T. Baker), sodium carbonate $\left(\mathrm{Na}_{2} \mathrm{CO}_{3}\right.$, Sigma-Aldrich), Folin \& Ciocalteu's phenol reagent (Sigma-Aldrich), gallic acid $\left((\mathrm{HO})_{3} \mathrm{C}_{6} \mathrm{H}_{2} \mathrm{CO}_{2} \mathrm{H}\right.$, Sigma-Aldrich), potassium sodium tartrate tetrahydrate $\left(\mathrm{KOCOCH}(\mathrm{OH}) \mathrm{CH}(\mathrm{OH}) \mathrm{COONa} \times 4 \mathrm{H}_{2} \mathrm{O}\right.$, Sigma-Aldrich), 3,5-dinitrosalicylic acid $\left(\left(\mathrm{O}_{2} \mathrm{~N}\right)_{2} \mathrm{C}_{6} \mathrm{H}_{2}-2-(\mathrm{OH}) \mathrm{CO}_{2} \mathrm{H}\right.$, Sigma-Aldrich), glucose $\left(\mathrm{C}_{6} \mathrm{H}_{12} \mathrm{O}_{6}\right.$, Sigma-Aldrich), phenol $\left(\mathrm{C}_{6} \mathrm{H}_{5} \mathrm{OH}\right.$, Sigma-Aldrich), sodium sulfite $\left(\mathrm{Na}_{2} \mathrm{SO}_{3}\right.$, Panreac), kuromanin chloride (cyanidin-3-O-glucoside, $\mathrm{C}_{21} \mathrm{H}_{21} \mathrm{O}_{11} \mathrm{Cl}, \geq 96 \%$, Extrasynthese, Lyon, France), and oenin chloride (malvidin-3-O-glucoside, $\mathrm{C}_{23} \mathrm{H}_{25} \mathrm{O}_{12} \mathrm{Cl}, \geq 97 \%$, Extrasynthese). Acetonitrile (ACN, LC-MS grade, Sigma-Aldrich), methanol (MeOH, LC-MS grade, Sigma-Aldrich), and water $\left(\mathrm{H}_{2} \mathrm{O}\right.$, Thermo Fischer Scientific, Waltham, MA, USA) were used as elution solvents during liquid chromatography. 
The nine materials investigated were the Amberite XAD 2 (Sigma-Aldrich), Amberlite IRA $400 \mathrm{Cl}^{-}$ (Sigma-Aldrich), Lewatit MDS TP 208 (Lanxess AG, Cologne, Germany), Lewatit MDS TP 260 (Lanxess AG), Chromosorb G-HP (Sigma-Aldrich), Zeocros CA 150 (PQ Corporation, Rolle, Switzerland), Activated Carbon (Chemviron Carbon, Brussels, Belgium), Oasis HLB (Waters Corporation, Milford, MA, USA), and Isolute C8 (EC) (Biotage, Sweden), Table 1.

Table 1. Physical properties and structural characteristics of tested materials.

\begin{tabular}{clccc}
\hline \multicolumn{1}{c}{ Material } & \multicolumn{1}{c}{ Material Details } & $\begin{array}{c}\text { Pore Diameter } \\
(\AA)\end{array}$ & $\begin{array}{c}\text { Particle } \\
\text { Diameter }(\mu \mathrm{m})\end{array}$ & $\begin{array}{c}\text { Surface Area } \\
\left(\mathbf{m}^{2} \cdot \mathbf{g}^{-1}\right)\end{array}$ \\
\hline Chromosorb G-HP & $\begin{array}{l}\text { Acid washed and treated with } \\
\text { dimethyldichlorosilane }\end{array}$ & Unknown & $125-149$ & 0.5 \\
\hline Amberite XAD 2 & $\begin{array}{l}\text { Hydrophobic crosslinked polystyrene copolymer } \\
\text { resin styrene-divinylbenzene (macroreticular) }\end{array}$ & 90 & $260-840$ & 300 \\
\hline $\begin{array}{c}\text { Amberlite IRA } \\
\text { 400 Cl }\end{array}$ & Styrene-divinylbenzene (gel) anion exchange column & Unknown & $20-25$ & - \\
\hline Lewatit TP 208 & $\begin{array}{l}\text { Weakly acidic, macroporous cation exchange resin } \\
\text { with chelating imino-diacetate groups }\end{array}$ & Unknown & $390( \pm 30)$ & - \\
\hline Lewatit TP 260 & $\begin{array}{l}\text { Weakly acidic, macroporous cation exchange resin } \\
\text { with chelating amino methylphosphonic acid groups }\end{array}$ & Unknown & $420( \pm 50)$ & - \\
\hline Zeocros CA 150 & Zeolite & Unknown & $3-5$ & - \\
\hline Activated Carbon & Activated carbon & Unknown & $150-250$ & 800 \\
\hline Oasis HLB & $\begin{array}{l}\text { Two monomers, the hydrophilic } N \text {-vinylpyrrolidone } \\
\text { and the lipophilic divinylbenzene }\end{array}$ & 80 & 30 & 500 \\
\hline Isolute C8 (EC) & $\begin{array}{l}\text { Medium retentive, non-polar sorbent for extraction. } \\
\text { Octyl (end-capped) }\end{array}$ & 60 & 50 & - \\
\hline
\end{tabular}

\subsection{Extraction Procedure}

The solid byproducts were stored at freezer $\left(-20^{\circ} \mathrm{C}\right)$. Amount of these byproducts was freezedried and the resulted powder was collected and stored at fridge $\left(5^{\circ} \mathrm{C}\right)$. The analogy between the amount before the freeze drying, and the resulted powder was 3 to 1 . Amount of the powder $(500 \mathrm{mg})$ was mixed with the extraction solution $(20 \mathrm{~mL})$ of acidified water with $5 \% v / v$ ortho-phosphoric acid $\left(\mathrm{H}_{3} \mathrm{PO}_{4} 85 \%\right)$. The mixture was vortexed, transferred to an ultrasound bath for $10 \mathrm{~min}$, and consequently to a water bath at $45^{\circ} \mathrm{C}$ for $2 \mathrm{~h}$. The next step was the centrifugation of the mixture at $4000 \mathrm{rpm}$ for $10 \mathrm{~min}$ and the collection of the supernatant. The procedure was repeated enough times in order to collect the necessary amount of extract for the scheduled studies.

The specific extraction solution was selected in order to facilitate the adsorption of the compounds of interest to the tested materials.

\subsection{Pretreatment of Solid Phase Materials and Evaluation Tests}

The resins were pretreated and activated according to the manufacturer's recommendation. At first, resins were soaked in methanol overnight. After soaking they were packed into plastic syringe tubes with glass microfiber filters (Whatman, Little Chalfont, UK). The resulting material volume into the SPE columns were between 0.75 and $0.85 \mathrm{~cm}^{3}$. After filling, the SPE columns were rinsed with water, and equilibrated with four bed volumes (BV) of $\mathrm{H}_{2} \mathrm{O}+5 \% v / v$ ortho-phosphoric acid $\left(\mathrm{H}_{3} \mathrm{PO}_{4}\right.$ $85 \%$ ), which was the solvent used during extraction procedure. The pretreatment of ion exchange resins was constituted of four extra steps that were performed between the steps of rinsing with water and before the equilibration of the column. The cation exchange resins were treated with $2 \mathrm{BV}$ of $4 \%$ $w / v \mathrm{NaOH}$ solution, then rinsed with $4 \mathrm{BV}$ of deionised water. Afterward, these were treated with $2 \mathrm{BV}$ of a $4 \% v / v \mathrm{HCl}$ solution, and then rinsed again with $5 \mathrm{BV}$ of water. The same procedure, but using the $\mathrm{NaOH}$ and $\mathrm{HCl}$ solutions in reverse order, was applied during the activation of the anion exchange resins.

The collected byproducts' extract was the substrate used during the evaluation tests on the selected resins. The pretreatment of the materials was followed by a three steps procedure. In the 
first step, 1.3 BV of sample was passed through each column. The second step was the washing of the column with $1.3 \mathrm{BV}$ of $\mathrm{H}_{2} \mathrm{O}$, and the third step was the elution with $1.3 \mathrm{BV}$ of acidified ethanol solution ( $3 \% v / v$ formic acid). After every step, the eluents of the columns were collected and stored for the subsequent analytical procedures.

\subsection{Analytical Procedures for Total Anthocyanins, Phenolic Content, and Sugars Determination}

Total anthocyanins, phenolic content, and sugars were determined in byproducts extract and at the eluents collected after SPE procedure. The methods used were the pH-differential method, Folin-Ciocalteu (FC) method, and dinitrosalicylic acid method respectively.

pH-differential method: The total anthocyanin content was determined using the pH-differential method [32] using a UV-vis spectrophotometer (Jenway 6300, Staffordshire, UK). This method is based at the property of anthocyanins to alter their structure in different $\mathrm{pH}$ conditions, resulting in a change in their color. In brief, two dilutions of the sample were prepared using buffer solutions, one at $\mathrm{pH}=1$ and another at $\mathrm{pH}=4.5$, and the absorbances of these solutions at $510 \mathrm{~nm}$ and at $700 \mathrm{~nm}$ were measured. Anthocyanin content was calculated as cyanidin-3-O-glucoside equivalents using an extinction coefficient of $26,900 \mathrm{~L} \cdot \mathrm{mol}^{-1} \cdot \mathrm{cm}^{-1}$ and molecular weight of 449 .

Folin-Ciocalteu (FC) method: The phenolic content was determined using the Folin-Ciocalteu (FC) method. In brief, a calibration curve was made using gallic acid solutions. In a test tube $0.2 \mathrm{~mL}$ of the sample were added, followed by $2.6 \mathrm{~mL} \mathrm{H} \mathrm{H}_{2} \mathrm{O}, 2 \mathrm{~mL} \mathrm{Na}_{2} \mathrm{CO}_{3}$ of a $(7 \% \mathrm{w} / \mathrm{v})$ solution and $0.2 \mathrm{~mL}$ of FC reagent. The mixture left in the dark for $90 \mathrm{~min}$. The absorbance of the mixture at $745 \mathrm{~nm}$ was measured [18].

Dinitrosalicylic acid (DNS) method: The sugars were determined using the Dinitrosalicylic acid method. In brief, a calibration curve was made using glucose solutions. A solution containing $1 \%$ DNS, $0.2 \%$ phenol, $0.05 \% \mathrm{Na}_{2} \mathrm{SO}_{3}$, and $1 \% \mathrm{NaOH}$ was prepared. In a test tube, $1.5 \mathrm{~mL}$ of the sample with $1.5 \mathrm{~mL}$ of the previous prepared solution were mixed. The mixture was heated for $5 \mathrm{~min}$ at $100{ }^{\circ} \mathrm{C}$ in a water bath. Afterwards $0.5 \mathrm{~mL}$ of a $40 \% w / v$ potassium sodium tartrate solution was added and the mixture was left at room temperature before the absorbance measurement at $575 \mathrm{~nm}$ [33].

\subsection{LC-PDA-MS Analysis}

The obtained extract along with the collected ethanolic elutions of Oasis HLB and Isolute C8 (EC) columns were filtered through a $0.45 \mu \mathrm{m}$ syringe filter (BGB Analytik, Richmond, VA, USA) and analyzed for their anthocyanin content using an LC-PDA-MS method. A Shimadzu LCMS-2010 EV, using electrospray ionization (ESI) process and a quadrupole mass analyser, equipped with an SPD-M20A PDA (Shimadzu Corporation, Kyoto, Japan) detector, at positive ionization mode was used for the chromatographic separation and identification of the compounds while the chromatographic column used was a Dionex, RP-C18, Acclaim 120, $150 \times 4.6 \mathrm{~mm} \times 5 \mu \mathrm{m}$ (Thermo Fisher Scientific, Waltham, MA, USA). A gradient elution program was employed, using water/formic acid $(99 / 1, v / v)$ and acetonitrile/formic acid $(99 / 1, v / v)$ as elution solvents, while the sample injection volume was $20 \mu \mathrm{L}$. The flow rate was $0.5 \mathrm{~mL} \cdot \mathrm{min}^{-1}$ with a $45 \mathrm{~min}$ gradient elution program as follows: $0 \mathrm{~min}$, 10\% B; 0-5 $\min , 10 \%-22 \%$ B; 5-14 $\min , 22 \%-28 \%$ B; $14-35 \mathrm{~min}, 28 \%-42 \%$ B; 35-40 min, 42\%-100\% B; 40-45 $\min , 100 \%-10 \%$ B.

\section{Results and Discussion}

\subsection{Preliminary Experiments for All Tested Materials}

Nine materials were studied in total. The reasoning for the selection of the specific materials was twofold. First of all, it was intended to select materials with different chemical and physical properties. The nine tested resins differ in chemical structure, polarity, particle size, surface area and retain mechanism, covering a wide range of different materials. Having this as priority it was not possible to test various materials from every category but we were constrained to select just some typical 
examples from each one (only one anion exchange column, only one type of zeolite and activated carbon). Secondly, we preferred to study materials that had not been already extensively studied in the past, like the XAD-7 by Kraemer-Schafhalter et al. [22] considering preferable to investigate the effectiveness of other materials.

During the experiments in first part of the study the byproducts' extract and the eluents collected after SPE procedure were analyzed for their anthocyanin, phenolic, and sugar content with the methods described at subsection 2.4. There are three types of collected and analyzed eluents: the sample eluent, the $\mathrm{H}_{2} \mathrm{O}$ eluent, and the ethanol eluent. The sample eluent is the eluent collected after the loading of the sample into the SPE column and its content corresponds to the compounds that were not retained from the column material. The $\mathrm{H}_{2} \mathrm{O}$ eluent is the eluent collected after the water loading and its content corresponds to the compounds that were not strongly bound to the column material. The ethanol eluent is the eluent collected after the ethanol loading into the column and its content corresponds to the compounds that were bound to the column material but were able to be recovered relatively easy with the use of ethanol.

There is also the sorption percentage of each material. This percentage corresponds to the amount of compounds that were bounded in the column and were not eluted in the sample eluent regardless if these were collect during second, third step, or even at all.

The results of the analyses performed to the specific eluents are expressed as the percentage of compounds detected in each collected eluent in comparison with the amount of the same compounds present at the loaded extract. Results are presented at Tables $2-4$.

Table 2. Anthocyanins determined in the eluents in comparison with the anthocyanins loaded to the SPE column.

\begin{tabular}{|c|c|c|c|c|c|}
\hline Material & $\begin{array}{c}\text { Sample Eluent } \\
\text { (1st Step) }\end{array}$ & $\begin{array}{c}\mathrm{H}_{2} \mathrm{O} \text { Eluent } \\
\text { (2nd Step) }\end{array}$ & $\begin{array}{l}\text { EtOH Eluent } \\
\text { (3rd Step) }\end{array}$ & $\begin{array}{c}\text { Total } \\
\text { Recovery }\end{array}$ & $\begin{array}{c}\text { Sorption } \\
\text { Percentage }\end{array}$ \\
\hline Chromosorb G-HP & $46 \%$ & $25 \%$ & $20 \%$ & $91 \%$ & $54 \%$ \\
\hline Amberite XAD 2 & $47 \%$ & $9.2 \%$ & $24 \%$ & $80 \%$ & $53 \%$ \\
\hline Amberlite IRA $400 \mathrm{Cl}^{-}$ & $65 \%$ & $4.6 \%$ & $3.3 \%$ & $73 \%$ & $35 \%$ \\
\hline Lewatit TP 208 & $36 \%$ & $11 \%$ & $5.2 \%$ & $52 \%$ & $64 \%$ \\
\hline Lewatit TP 260 & $41 \%$ & $6.8 \%$ & $12 \%$ & $60 \%$ & $59 \%$ \\
\hline Zeocros CA 150 & $23 \%$ & $10 \%$ & $53 \%$ & $86 \%$ & $77 \%$ \\
\hline Activated Carbon & $2.8 \%$ & $0.6 \%$ & $0.7 \%$ & $4.1 \%$ & $97 \%$ \\
\hline Oasis HLB & $0.6 \%$ & $4.9 \%$ & $83 \%$ & $89 \%$ & $99 \%$ \\
\hline Isolute C8 (EC) & $2.4 \%$ & $2.4 \%$ & $95 \%$ & $100 \%$ & $98 \%$ \\
\hline
\end{tabular}

Table 3. Total phenolics determined in the eluents in comparison with the total phenolics loaded to the SPE column.

\begin{tabular}{cccccc}
\hline Material & $\begin{array}{c}\text { Sample Eluent } \\
\text { (1st Step) }\end{array}$ & $\begin{array}{c}\mathbf{H}_{\mathbf{2}} \text { O Eluent } \\
\text { (2nd Step) }\end{array}$ & $\begin{array}{c}\text { Eluent Eluent } \\
\text { (3rd Step) }\end{array}$ & $\begin{array}{c}\text { Total } \\
\text { Recovery }\end{array}$ & $\begin{array}{c}\text { Sorption } \\
\text { Percentage }\end{array}$ \\
\hline Chromosorb G-HP & $52 \%$ & $30 \%$ & $17 \%$ & $99 \%$ & $48 \%$ \\
Amberite XAD 2 & $48 \%$ & $13 \%$ & $18 \%$ & $79 \%$ & $52 \%$ \\
Amberlite IRA 400 Cl & $58 \%$ & $22 \%$ & $8.4 \%$ & $88 \%$ & $42 \%$ \\
Lewatit TP 208 & $66 \%$ & $31 \%$ & $1.6 \%$ & $99 \%$ & $34 \%$ \\
Lewatit TP 260 & $59 \%$ & $22 \%$ & $5.3 \%$ & $86 \%$ & $41 \%$ \\
Zeocros CA 150 & $51 \%$ & $38 \%$ & $8.6 \%$ & $98 \%$ & $49 \%$ \\
Activated Carbon & $1.0 \%$ & $0.9 \%$ & $1.4 \%$ & $3.3 \%$ & $99 \%$ \\
Oasis HLB & $2.6 \%$ & $3.9 \%$ & $19 \%$ & $26 \%$ & $97 \%$ \\
Isolute C8 (EC) & $3.5 \%$ & $6.7 \%$ & $87 \%$ & $97 \%$ & $97 \%$ \\
\hline
\end{tabular}


Table 4. Sugars determined in the eluents in comparison with the sugars loaded to the SPE column.

\begin{tabular}{cccccc}
\hline Material & $\begin{array}{c}\text { Sample Eluent } \\
\text { (1st Step) }\end{array}$ & $\begin{array}{c}\mathbf{H}_{\mathbf{2}} \mathbf{O} \text { Eluent } \\
\text { (2nd Step) }\end{array}$ & $\begin{array}{c}\text { Eluent Eluent } \\
\text { (3rd Step) }\end{array}$ & $\begin{array}{c}\text { Total } \\
\text { Recovery }\end{array}$ & $\begin{array}{c}\text { Sorption } \\
\text { Percentage }\end{array}$ \\
\hline Chromosorb G-HP & $59 \%$ & $30 \%$ & $11 \%$ & $100 \%$ & $41 \%$ \\
Amberite XAD 2 & $64 \%$ & $21 \%$ & $14 \%$ & $99 \%$ & $36 \%$ \\
Amberlite IRA 400 Cl- & $65 \%$ & $10 \%$ & $4.9 \%$ & $80 \%$ & $35 \%$ \\
Lewatit TP 208 & $68 \%$ & $24 \%$ & $4.1 \%$ & $96 \%$ & $32 \%$ \\
Lewatit TP 260 & $60 \%$ & $14 \%$ & $6.1 \%$ & $80 \%$ & $40 \%$ \\
Zeocros CA 150 & $61 \%$ & $32 \%$ & $5.4 \%$ & $98 \%$ & $39 \%$ \\
Activated Carbon & $2.5 \%$ & $3.6 \%$ & $7.2 \%$ & $13 \%$ & $98 \%$ \\
Oasis HLB & $33 \%$ & $26 \%$ & $3.9 \%$ & $63 \%$ & $67 \%$ \\
Isolute C8 (EC) & $33 \%$ & $19 \%$ & $26 \%$ & $78 \%$ & $67 \%$ \\
\hline
\end{tabular}

\subsubsection{Test Results Evaluation}

Anthocyanin content tests results evaluation: Based on the obtained results, the nine resins can be divided into three categories regarding the resulting anthocyanin concentration in the ethanolic eluent. Oasis HLB and Isolute C8 (EC) are classified in the first category as the most effective resins with recovery rates above $80 \%$. In the middle category belong the Zeocros CA 150, the Amberite XAD 2, and the Chromosorb G-HP with recoveries between $20 \%$ and $53 \%$, while the rest resins could belong to the third group with recovery rates below $20 \%$.

Total phenolic content tests results evaluation: Using the same methodology as for anthocyanin content tests results evaluation, in this case the nine resins can be divided in two categories regarding the resulting total phenolic concentration in the ethanolic eluent. Only the Isolute C8 (EC) can be classified to the higher category with a recovery rate above $80 \%$, while all other materials exhibited rates below $20 \%$.

Sugar content tests results evaluation: Following the same classification criteria, the nine resins are divided again in two categories regarding the resulting sugar concentration in the ethanolic eluent. Three materials exhibit recovery rates above $20 \%$, while the other 6 materials belong to the lower level with recoveries below $20 \%$.

\subsubsection{Materials Performance Remarks}

The ion selective materials exhibited poor recovery for all the investigated compounds, and especially the anion exchange resin (Amberlite IRA $400 \mathrm{Cl}^{-}$) showed very poor anthocyanins retention with high color losses. The poor performance of ion selective resins comes in agreement with the observations of Schafhalter et al. [22]. In their research all three tested anion exchange resins exhibited color loss, while none of the cation exchange resins tested showed remarkable performance.

The Chromosorb G-HP also exhibited inefficient anthocyanins retention, while a significant percentage of all three compound groups were eluting during water elution at the second step of the test procedure. This is probably due to the very small surface area of this material, taking into consideration that the surface area has been proved to be one of the main parameters affecting the anthocyanin absorbance $[23,28]$.

The Amberlite XAD 2, a polystyrene copolymer resin, displayed relative low anthocyanins recovery $(24 \%)$, but the total amount of anthocyanins eluted from the column during the three steps of the procedure was equal to $80 \%$ of the total anthocyanins load. This means that about $20 \%$ was still adsorbed in the resin, a quantity that could possibly be retrieved after further successive elutions, allowing the recovery of anthocyanins to approach or even outnumber $50 \%$ after optimizing the total procedure for the specific material. Furthermore, a big part of the $47 \%$ of anthocyanins eluting from the column during sample loading, could possibly be adsorbed after a second or a third successive adsorption cycle, since as Wang et al. [28], have noted the anthocyanin amount adsorbed to the resin is increasing rapidly during the first three cycles. 
The Zeocros CA150 achieved a quite satisfactory rate of anthocyanins recovery (53\%), while at the same time did not retain total phenolics and sugars at a significant extent $(<10 \%)$. This attribute makes it an ideal material for purposes of selective binding of anthocyanins towards other phenolic compounds and/or sugars. Similar behavior, but with even better performance characteristics $(83 \%)$, was exhibited in the Oasis HLB SPE column. On the other hand, the Isolute C8 (EC) showed similarly impressive results on the anthocyanins recovery (95\%), but without the selectivity exhibited towards them by Oasis HLB, since the rates for total phenolics and sugars were significantly higher, $87 \%$ and $26 \%$ respectively.

Activated carbon showed a unique behavior compared with all other tested materials. It adsorbed all the studied compounds and retain them tightly, making it an ideal material choice for specific purposes, like the removal of these compounds from a liquid stream or aqueous solutions. A similar behavior of activated carbon towards phenolic compounds of distilled grape pomace had been also observed by Soto et al. [21].

An outline of the main remarks for each material is presented in Table 5.

Table 5. General remarks regarding the materials tested during SPE procedure.

\begin{tabular}{cl}
\hline Material & Comment \\
\hline Chromosorb G-HP & Insufficient anthocyanins retention, compounds were eluted with water \\
Amberite XAD 2 & $\begin{array}{l}\text { Relative low anthocyanins recovery but with 20\% still absorbent in the material meaning that } \\
\text { with successive elutions the recovery rate could probably approach } 45 \%\end{array}$ \\
Amberlite IRA 400 Cl & - \\
Lewatit TP 208 & Poor retention, high color losses \\
Lewatit TP 260 & Poor retention \\
Zeocros CA 150 & Poor retention \\
Activated Carbon & Almost quantitatively absorbance of all investigated compounds, ideal for cleaning purposes \\
Oasis HLB & Great anthocyanins recovery, good separation from other phenolics and sugars \\
Isolute C8 (EC) & Great anthocyanins and total phenolics recovery, $\frac{1}{4}$ of sugars recovered \\
\hline
\end{tabular}

The Oasis HLB and Isolute C8 (EC) columns were the materials with the higher anthocyanins recovery rates and since anthocyanins were the main area of interest of this research, these materials were selected for further studies during the second part of the study.

\subsection{OASIS HLB and ISOLUTE C8 (EC) Further Studies}

During the second part of our study, additional experiments were conducted in order to calculate the anthocyanins capacity of Oasis HLB and Isolute C8 (EC), as well as to investigate the behavior of these materials towards the dominant anthocyanins of the extract using an LC-PDA-MS system.

In order to determine the sorbing capacities of the materials, small portions of the extract (1 BV each time) were loaded to the SPE columns until color loss started to occur. When the columns started to elute reddish color after sample loading, it was considered that the material was not able to retain any more anthocyanins without significant losses, and the procedure was considered complete. In total more than $30 \mathrm{~mL}$ of aqueous extract was passed through Isolute C8 (EC) column and more than $50 \mathrm{~mL}$ through Oasis HLB. When the sample loading procedure was completed for each material, the elution step came next. The elution of the adsorbed anthocyanins from the Isolute C8 (EC) and the Oasis HLB SPE columns was done using only $1.5 \mathrm{~mL}$ and $3.0 \mathrm{~mL}$ of acidified ethanol respectively. That equals to an enrichment factor of more than 14 for the first and 12 times for the second material, also taking into account the recovery rates. The anthocyanins amount loaded to the column, as well as the amount eluted, the recovery rate, and the capacity of each material are presented in Table 6. 
Table 6. Determination of anthocyanins capacity of Oasis HLB and Isolute C8 (EC) materials.

\begin{tabular}{cccccc}
\hline Material & $\begin{array}{c}\text { Material } \\
\text { Volume }\end{array}$ & $\begin{array}{c}\text { Anthocyanins } \\
\text { Amount Loaded }\end{array}$ & $\begin{array}{c}\text { Anthocyanins } \\
\text { Amount Eluted }\end{array}$ & $\begin{array}{c}\text { Recovery } \\
\text { Rate }\end{array}$ & $\begin{array}{c}\text { Material Anthocyanins } \\
\text { Capacity }\end{array}$ \\
\hline Oasis HLB & $0.8 \mathrm{~cm}^{3}$ & $6.36 \mathrm{mg}$ & $4.61 \mathrm{mg}$ & $72.5 \%$ & $5.76 \mathrm{mg} \cdot \mathrm{cm}^{-3}$ \\
Isolute C8 (EC) & $0.8 \mathrm{~cm}^{3}$ & $3.51 \mathrm{mg}$ & $2.45 \mathrm{mg}$ & $69.8 \%$ & $3.06 \mathrm{mg} \cdot \mathrm{cm}^{-3}$ \\
\hline
\end{tabular}

The Oasis HLB not only proved to have higher capacity compared with the Isolute C8 (EC), $5.76 \mathrm{mg} \cdot \mathrm{cm}^{-3}$ to $3.06 \mathrm{mg} \cdot \mathrm{cm}^{-3}$, but also achieved a higher recovery rate of $72.5 \%$ compared to $69.8 \%$. The higher capacity of the Oasis HLB over the Isolute C8 (EC) column could be attributed to the larger surface area of the first $\left(800 \mathrm{~m}^{2} \cdot \mathrm{g}^{-1}\right.$ towards $\left.500 \mathrm{~m}^{2} \cdot \mathrm{g}^{-1}\right)$, since this feature has been characterized as the most $[23,27,28]$ or one of the two most [26] decisive parameter affecting the adsorption capacity of a resin.

The collected eluents were analyzed for their anthocyanin content with an LC-PDA-MS system in order to investigate how the solid phase extraction procedure using the specific materials affects the anthocyanins of a grape pomace extract. In order to do so, four malvidin based anthocyanins (the dominant anthocyanins in wine and wine byproducts) were selected for comparison studies. These were the Malvidin-3-O-glucoside, Vitisin B (Malvidin derivative), Malvidin-3-(6" -acetylglucoside), and Malvidin-3-(6"-p-coumaroylglucoside), (Table 7).

Table 7. Results after LC-PDA-MS analyses.

\begin{tabular}{|c|c|c|c|c|}
\hline \multirow[t]{2}{*}{ Parameter } & \multicolumn{4}{|c|}{ Compound } \\
\hline & Mv-3-O-glucoside & $\begin{array}{l}\text { Vitisin } \mathrm{B}(\mathrm{Mv} \\
\text { derivative })\end{array}$ & Mv-3-(6" -acetylglucoside) & Mv-3-(6" $-p$-coumaroylglucoside $)$ \\
\hline Molecular weight & 493 & 517 & 535 & 639 \\
\hline $\begin{array}{l}\text { Anthocyanins amount } \\
\text { loaded to Oasis HLB }\end{array}$ & $2179 \mu \mathrm{g}$ & $441.3 \mu \mathrm{g}$ & $1251 \mu \mathrm{g}$ & $301.6 \mu \mathrm{g}$ \\
\hline $\begin{array}{l}\text { Anthocyanins amount } \\
\text { eluted from Oasis HLB }\end{array}$ & $1006 \mu \mathrm{g}$ & $274.5 \mu \mathrm{g}$ & $1158 \mu \mathrm{g}$ & $290.1 \mu \mathrm{g}$ \\
\hline Recovery rate & $46.2 \%$ & $62.2 \%$ & $92.6 \%$ & $96.2 \%$ \\
\hline $\begin{array}{c}\text { Anthocyanins amount } \\
\text { loaded to Isolute C8 (EC) }\end{array}$ & $1315 \mu \mathrm{g}$ & $227.9 \mu \mathrm{g}$ & $735.7 \mu \mathrm{g}$ & $161.5 \mu \mathrm{g}$ \\
\hline $\begin{array}{c}\text { Anthocyanins amount } \\
\text { eluted from Isolute C8 (EC) }\end{array}$ & $547.9 \mu \mathrm{g}$ & $152.6 \mu \mathrm{g}$ & $655.5 \mu \mathrm{g}$ & $153.9 \mu \mathrm{g}$ \\
\hline Recovery rate & $41.7 \%$ & $67.0 \%$ & $89.1 \%$ & $95.3 \%$ \\
\hline
\end{tabular}

As can be seen in Table 7, there is a trend observed in the behavior of both examined materials. In both cases, the recovery rates increased as the molecular weight of the studied compound increased. For the Oasis HLB it starts from $46.2 \%$ for Mv-3-O-glucoside (Molecular weight (MW): 493) and it reaches up to $96.2 \%$ for Mv-3-(6" ${ }^{\prime \prime}-p$-coumaroylglucoside) (MW: 639), while for the Isolute C8 (CE) the rates are $41.7 \%$ and $95.3 \%$ respectively.

This pattern can probably be attributed to the pore diameter of the materials since the pore diameter plays a crucial role to the SPE procedure. If it is too small, the molecules are not be able to penetrate into the pores, or their diffusion is restricted. On the other hand, if the pore diameter is too big the molecules are not able to adsorb and are eluted faster and more easily than intended. In our case, the elution pattern indicated that the lower MW molecules were adsorbed less tightly in the column, resulting to a gradual elution of them during the subsequent sample loading rounds.

\section{Conclusions}

Three ion selective and six sorbing materials with different chemical and physical properties were evaluated in this study for their ability to retain and desorb anthocyanins, total phenolics, and sugars from an aqueous solution during an SPE procedure. The sample used was an extract from 
grape pomace, while the selected resins covered a wide range of materials, with different chemical and physical properties, from ion exchange resins, to zeolite, activated carbon, and polystyrene resins.

The materials were divided into three categories based on the compounds concentration in the ethanolic eluent. The higher category included materials with recovery rates above $80 \%$, the middle category with recovery rates between $20 \%$ and $80 \%$, and the lower one with recovery rates under $20 \%$. Regarding anthocyanins the materials were distributed to all three categories, with two materials in the higher, three in the middle, and four in the lower category. For total phenolics, only Isolute C8 (EC) exhibited recovery rate above $80 \%$, while for sugars there were no materials at the top category. Though the focus of this study was not to optimize the conditions of the SPE procedure, the relative recovery rates of the resins were compared to help identify the most effective materials for further research.

The two materials with the best performance regarding anthocyanins, Oasis HLB and Isolute C8 (EC), were further investigated for their anthocyanin capacity and the way they interact with anthocyanins of different molecular weight. Results showed capacities of $5.76 \mathrm{mg} \cdot \mathrm{cm}^{-3}$ and $3.06 \mathrm{mg} \cdot \mathrm{cm}^{-3}$ for Oasis HLB and Isolute C8 (EC) respectively, while the pattern detected showed an increasing recovery rate for anthocyanins of higher molecular weight for both materials, something that could be attributed to their pore sizes.

As far as we know, it is the first time that these two commercial available materials, Oasis HLB and Isolute C8 (EC), have been tested for their ability to retain and elute anthocyanins from wine byproducts extract. Furthermore, instead of focusing our study on a specific category of materials, like other similar studies have done, we decided to follow a different approach by comparing the performance of materials with different physicochemical properties.

Acknowledgments: This work was supported by "11SYN_2_1992" action "COOPERATION 2011" of EYDE-ETAK funded by the Operational Program "Competitiveness and Entrepreneurship" (EPAN-II).

Author Contributions: Evangelos D. Trikas, Rigini M. Papi, Dimitrios A. Kyriakidis, and George A. Zachariadis conceived and designed the experiments; Evangelos D. Trikas performed the experiments as part of his Ph.D. thesis, analyzed the data, and wrote the paper.

Conflicts of Interest: The authors declare no conflict of interest

\section{Abbreviations}

The following abbreviations are used in this manuscript:

$\begin{array}{ll}\text { Mv } & \text { Malvidin } \\ \text { SPE } & \text { solid-phase extraction } \\ \text { LC } & \text { liquid chromatography } \\ \text { PDA } & \text { photodiode array } \\ \text { MS } & \text { mass spectrometry } \\ \text { BV } & \text { bed volume } \\ \text { FC } & \text { Folin-Ciocalteu }\end{array}$

\section{References}

1. Alonso, A.; Guillean, D.; Barroso, C.; Puertas, B.; Garcia, A. Determination of antioxidant activity of wine byproducts and its correlation with polyphenolic content. J. Agric. Food. Chem. 2002, 50, 5832-5836. [CrossRef] [PubMed]

2. Llobera, A.; Canellas, J. Antioxidant activity and dietary fibre of Prensal Blanc white grape (Vitis vinifera) byproducts. Int. J. Food. Sci. Technol. 2008, 43, 1953-1959. [CrossRef]

3. Trikas, E.; Melidou, M.; Rigini, P.; Zachariadis, G.; Kyriakidis, D. Extraction, separation and identification of anthocyanins from red wine byproduct and their biological activities. J. Funct. Foods. 2016, 25, 548-558. [CrossRef]

4. Sanhueza, L.; Tello, M.; Vivanco, M.; Mendoza, L.; Wilkens, M. Relation between antibacterial activity against food transmitted pathogens and total phenolic compounds in grape pomace extracts from Cabernet Sauvignon and Syrah Varieties. Adv. Microb. 2014, 4, 225-232. [CrossRef] 
5. Baydar, N.G.; Ozkan, G.; Sagdic, O. Total phenolic contents and antibacterial activities of grape (Vitis vinifera L.) extracts. Food Control 2004, 15, 335-339. [CrossRef]

6. Schab, D.W.; Trinh, N.H. $\Delta$ o artificial food colors promote hyperactivity in children with hyperactive syndromes? A meta-analysis of double-blind placebo-controlled trials. J. Dev. Behav. Pediatr. 2004, 25, 423-434. [CrossRef] [PubMed]

7. Giusti, M.M.; Wrolstad, R.E. Acylated anthocyanins from edible sources and their applications in food systems. Biochem. Eng. J. 2003, 14, 217-225. [CrossRef]

8. Pazmino-Duran, A.E.; Giusti, M.M.; Wrolstad, R.E.; Gloria, M. Anthocyanins from Oxalis triangularis as potential food colorants. Food Chem. 2001, 75, 211-216. [CrossRef]

9. Corrales, M.; Garcia, A.; Butz, P.; Tauscher, B. Extraction of anthocyanins from grape skins assisted by high hydrostatic pressure. J. Food Eng. 2009, 90, 415-421. [CrossRef]

10. Acevedo, A.; Hilbert, G.; Riviere, C.; Mengin, V.; Ollat, N.; Bordenave, L.; Decroocq, S.; Delaunay, J.; Delrot, S.; Merillon, J.; et al. Anthocyanin identification and composition of wild Vitis spp. accessions by using LC-MS and LC-NMR. Anal. Chim. Acta 2012, 732, 145-152. [CrossRef] [PubMed]

11. Li, Z.; Pan, Q.; Cui, X.; Duan, C. Optimization on anthocyanins extraction from wine grape skins using orthogonal test design. Food Sci. Biotechnol. 2010, 19, 1047-1053. [CrossRef]

12. Corrales, M.; Toepfl, S.; Butz, P.; Knorr, D.; Tauscher, B. Extraction of anthocyanins from grape byproducts assisted by ultrasonics, high hydrostatic pressure or pulsed electric fields: A comparison. Innov. Food Sci. Emerg. Technol. 2008, 9, 58-91. [CrossRef]

13. Trikas, E.; Rigini, P.; Kyriakidis, D.; Zachariadis, G. A Sensitive LC-MS Method for Anthocyanins and Comparison of Byproducts and Equivalent Wine Content. Separations 2016, 3, 18. [CrossRef]

14. Kovacevic, D.; Putnik, P.; Dragovic-Uzelac, V.; Vahcica, N.; Babojelic, M.; Levaj, B. Influences of organically and conventionally grown strawberry cultivars on anthocyanins content and color in purees and low-sugar jams. Food Chem. 2015, 181, 94-100. [CrossRef] [PubMed]

15. Cao, J.; Li, X.; Liu, Y.; Leng, F.; Li, X.; Sun, C.; Chen, K. Bioassay-Based Isolation and Identification of Phenolics from Sweet Cherry That Promote Active Glucose Consumption by HepG2 Cells. J. Food Sci. 2015, 80. [CrossRef] [PubMed]

16. Deineka, V.; Deineka, L.; Sidorov, N.; KostenkoI, M.; Blinova, P. Estimating the Solubility of Anthocyanins Using Cartridges for Solid-Phase Extraction. Russ. J. Phys. Chem. A 2016, 90, 861-863. [CrossRef]

17. Diaz-Reinoso, B.; Gonzalez-Lopez, N.; Moure, A.; Dominguez, H.; Parajo, J.C. Recovery of antioxidants from industrial waste liquors using membranes and polymeric resins. J. Food Eng. 2010, 96, 127-133. [CrossRef]

18. Soto, M.L.; Conde, E.; Gonzalez-Lopez, N.; Conde, M.J.; Moure, A.; Sineiro, J.; Falque, E.; Dominguez, H.; Nunez, M.J.; Parajo, J.C. Recovery and Concentration of Antioxidants from Winery Wastes. Molecules 2012, 17, 3008-3024. [CrossRef] [PubMed]

19. Kammerer, J.; Schweizer, C.; Carle, R.; Kammerer, D.R. Recovery and fractionation of major apple and grape polyphenolsfrom model solutions and crude plant extracts using ion exchange and adsorbent resins. Int. J. Food Sci. Technol. 2011, 46, 1755-1767. [CrossRef]

20. Wang, B. Orthogonal test design for optimisation of extraction of trans-resveratrol from Pinot Noirgrape pomace. Nat. Prod. Res. 2012, 9, 821-829. [CrossRef] [PubMed]

21. Soto, M.L.; Moure, A.; Dominguez, H.; Parajo, J.C. Charcoal adsorption of phenolic compounds present in distilled grape pomace. J. Food Eng. 2008, 84, 156-163. [CrossRef]

22. Kraemer-Schafhalter, A.; Fuchs, H.; Pfannhauser, W. Solid-Phase Extraction (SPE) a Comparison of 16 Materials for the Puriücation of Anthocyanins from Aronia melanocarpa var Nero. J. Sci. Food Agric. 1998, 78, 435-440. [CrossRef]

23. Sandhu, A.K.; Gu, L. Adsorption/Desorption Characteristics and Separation of Anthocyanins from Muscadine (Vitis rotundifolia) Juice Pomace by Use of Macroporous Adsorbent Resins. J. Agric. Food Chem. 2013, 61, 1441-1448. [CrossRef] [PubMed]

24. Kammerer, D.; Kljusuric, J.G.; Carle, R.; Schieber, A. Recovery of anthocyanins from grape pomace extracts (Vitis vinifera L. cv. Cabernet Mitos) using a polymeric adsorber resin. Eur. Food Res. Technol. 2005, 220, 431-437. [CrossRef]

25. Buran, T.J.; Sandhu, A.K.; Li, Z.; Rock, C.R.; Yang, W.W.; Gu, L. Adsorption/desorption characteristics and separation of anthocyanins and polyphenols from blueberries using macroporous adsorbent resins. J. Food Eng. 2014, 128, 167-173. [CrossRef] 
26. Liu, X.; Xiao, G.; Chen, W.; Xu, Y.; Wu, J. Quantification and Purification of Mulberry Anthocyanins With Macroporous Resins. J. Biomed. Biotechnol. 2004, 5, 326-331. [CrossRef] [PubMed]

27. Yang, Y.; Yuan, X.; Xu, Y.; Yu, Z. Purification of Anthocyanins from Extracts of Red Raspberry Using Macroporous Resin. Int. J. Food Prop. 2015, 18, 1046-1058. [CrossRef]

28. Wang, X.; Hansen, C.; Allen, K. Extraction of Anthocyanins from Black Bean Canning Wastewater with Macroporous Resins. J. Food Sci. 2014, 79, 184-188. [CrossRef] [PubMed]

29. Wang, X.; Hansen, C.; Allen, K. Identification of Anthocyanins Isolated from Black Bean Canning Wastewater by Macroporous Resin Using Optimized Conditions. Food Nutr. Sci. 2013, 4, 174-181. [CrossRef]

30. Mauro, A.; Arena, E.; Fallico, B.; Passerini, A.; Maccarone, E. Recovery of Anthocyanins from Pulp Wash of Pigmented Oranges by Concentration on Resins. J. Agric. Food Chem. 2002, 50, 5968-5974. [CrossRef] [PubMed]

31. Beye, C.; Tounkara, L.S.; Destain, J.; Zgoulli, S.; Ndoye, A.S.; Thonart, P. Study of the sorption behavior of hibiscus sabdariffa anthocyanins on a macroporous resin. J. Food Process. Eng. 2013, 36, 579-590.

32. Giusti, M.M.; Wrolstad, R.E. Characterization and measurement of anthocyanins by UVvisible spectroscopy. In Current Protocols in Food Analytical Chemistry; John Wiley \& Son: New York, NY, USA, 2001; p. 1000.

33. Mazauric, J.P.; Salmon, J.M. Interactions between yeast lees and wine polyphenols during simulation of wine aging. II. Analysis of desorbed polyphenol compounds from yeast lees. J. Agric. Food. Chem. 2006, 54, 3876-3881. [CrossRef] [PubMed]

(C) 2017 by the authors. Licensee MDPI, Basel, Switzerland. This article is an open access article distributed under the terms and conditions of the Creative Commons Attribution (CC BY) license (http:/ / creativecommons.org/licenses/by/4.0/). 